\section{A Perture}

ON

\section{THE DIAGNOSIS OF PULMONARY TUBERCULOSIS.}

\section{Delivered at the Medical Graduates' College and Polyclinic.}

By C. THEODORE WILLIAMS, M.D., F.R.C.P., Consulting Physician to the Hospital for Consumption and Diseases of

\section{Pathology.}

Gentremen,-According to modern pathology, pulmonary tuberculosis is due to attacks on the lungs by the tubercle bacillus. Whatever other organisms there may be mixed up with the tubercle bacillus they do not begin the original attack. There is no doubt that it is the invasion of the lungs by the tubercle bacillus that causes pulmonary tuberculosis. The tubercle bacillus enters the bronchi, passes down the terminal bronchioles, and, after increasing and multiplying, gives rise to irritative and pneumonic processes. In time a large amount of the various products of the bacillus are to be found, and when the process has continued some time, we are able to distinguish giant cells and the small celled infiltration which are characteristic of tubercle. I show you a very pretty sketch of the more acute process, where the masses of tubercle bacilli and the resulting cell proliferation are breaking through the wall of the alveolus. In an attack of tuberculosis, what is the first defence of the organism ? The idea is that human beings must inhale tubercle bacilli, just as they inhale other bacilli, whether derived from the dried sputum in the streets or whether from the wards or out-patient department of a hospital containing consumptives, or in places of public resort. It has been demonstrated that tubercle bacilli exist occasionally in the nasal secretion of healthy people, such as medical students in the wards. But why do not these people get tuberculosis? They do not; at all events, it is very rare for it to occur among them. Why do a certain number of people get tuberculosis through this inhalation? Beginning with the mouth, we must not forget that one of the defences against lung infection is the fact that there is a great deal of absorption from the mouth into the salivary and other glands; and there is no doubt that in a very large number of these children whom you see with enlarged glands, not only enlarged sub-maxillary glands but also cervical glands, they are due to absorption of tubercle bacilli from the mouth. I have seen children with enlarged cervical and sub-maxillary glands, and I have seen those glands removed, and sections prepared from them in which the tabercle bacilli could be clearly shown, and yet the lungs have never been affected. There is no doubt therefore that in such cases the disease of the lungs has been prevented by absorption into the glands. And we must never forget to examine the tonsils. Tuberculons disease of the tonsils is not very common, but every now and then one comes across a case, and I do not question the fact that the tonsils act as diverticula to the air passages, and receiving the bacilli, become infected. In the same way disease of the soft palate and of the pharynx takes place and results in ulceration, and also ulceration of the tongue of a tuberculous nature. These regions are often attacked by the tubercle bacilli primarily, and they may, like the glands, localize the disease for a time but they may also be affected secondarily from the lungs. We must also remember the defences of the air passage themselves to protect the lungs. There is no doubt that the nose protects to some extent, and the larynx must never be forgotten as a defence. Sometimes the bacilli attack the larynx first, though this is a rare event. But the greates protection of all is the trachea, and to a certain extent the primary bronchi. These have three layers of epithelium which have to be penetrated, and we know that the top layer of all is armed with ciliae, the ciliary movement promoting a strong current outwards, thus tending to prevent the tubercle bacilli from descending, and we can explain the disappearance of much dust from the lungs in that way. These defences must be taken into account when considering why it is that some people do not get tuberculosis, and why, although people are in the midst of infection, the disease is not so common as might be expected. We know that a large number of persons, certainly among those in consumption hospitals, must inhale a large number of tubercle bacilli. For instance, take the out.patient department of Brompton or Victoria Park Hospitals. Of the outpatients themselves, two-thirds are consumptives, and many of them have cavities, with much secretion, and thongh they are not allowed to spit about, yet handkerchiefs are brought out, with the sputum dried on them, and these are flicked about the room, so that some tuberculous dust must be disseminated in the air. Flügge's experiments showed that consumptives often during coughing ejected droplets of phlegm which contained tubercle bacilli. 1 think, therefore, you may take it for granted that the bacilli must be inhaled. In olden times, at the Brompton Hospital, before the infectious nature of the disease was known, there were not so many precautions taken as at present, and yet the carefully-taken statistics of the hospital during sixty years hardly show a case of tuberculosis which could be traced to infection at the hospital among the nurses, medical officers, house-physicians, and other residents. I think the figures show a smaller number of cases of tuberculous disease among the residents than in general hospitals, where the cases admitted are not chiefly those of consumption. So, if the disease is infectious, which, no doubt, it is to some extent, it must be very slightly so, and the lungs are probably protected in the way mentioned.

Another important question with regard to this disease is, How does the patient become weakened so as to be vulnerable? It is very difficult to say; but I think if you will inquire into the history of many of these cases of phthisis you will find that, especially among the poorer classes, the weakening is due more to general than to local causes. The chief predisposing causes of tubercle among the Brompl on patients appear to be two. One is impure air. Life in the very unhealthy atmosphere of crowded rooms, such as those occupied by milliners, seamstresses, and printers, especially in the old days, was a very prolific cause of tuberculosis. Parliamentary and private inquiries, such as those of the late Dr. Guy, show that it is a matter of experience that where the cubic space was below a certain limit for each worker, there was sure to be consumption. If these people are given plenty of fresh air, the amount of consumption either diminishes or disappears altogether. We know that in London the mortality from consumption depends almost entirely on the amount of crowding. The death-rate from consumption is not specially large in the districts where the great consumption hospitals like Brompton and Victoria Park are situated. In those districts the mortality is comparatively small. But in places like the Strand district and Southwark, where there is great crowding and very few open spaces, and where the cubic space in which people work is very small, the mortality from the disease is much greater. So the question of the prevalence of consumption rests very largely on the question of fresh air.

The other great predisposing cause is the lack of proper food. Over and over again you will find people whom you have known in good circumstances, doing well, and in good health, but who suddenly have a reverse in business and the previous prosperity gives place to poverty. When they lose their money they often have to take to unhealthy occupations. Moreover, in addition to this they often do not get enough food. Whereas they probably previously had two good meat meals a day, perhaps they are reduced now to one or no meat meals. One finds instances of poor women who have lost their money and who are living on tea and buns and such like horrors. In such cases you sometimes find the young man or the young woman who was apparently previously in good health, comes to you and on examination you note the lungs are the seat of tubercle. A very interesting example of that was given by the late Professor Peter, of Paris, in the case of a perfectly healthy man who had stricture of the oesophagus due to swallowing sulphuric acid. This led to starvation and he died after lingering for some months. When the lungs were examined post mortem they were found to bestaffed with recent tubercle. No mention is made of the treatment employed to introduce food. I donot know a more striking case to demonstrate how important is the question of food in this disease. There are, of course, other predisposing causes of tubercle, and one of these is the influence of those occupations in which the lungs are prevented from acting properly and fully. I mention this becanse I want to refer to Freund's researches on the matter. Dr. Freund ${ }^{1}$ states that certain changes take place in the upper ribs of consumptives, which are shown in the diagrams on p. 590 copied from his work. Freund says that what takes place is an ossification of the carlilages of the first and second ribs, and the consequence is that they shrink up and become much shorter, and sometimes the 
size of the cartilage from the end of the bone to the sternum is diminished two-thirds. But the great feature is that the cartilage gradually becomes ossified. It is the membranous form of ossification, the same as that which takes place in connexion : with the tables of bone in the skull. This deposit of bone is not at first all over the cartilaye, but over its anterior surface and gradually extending encloses

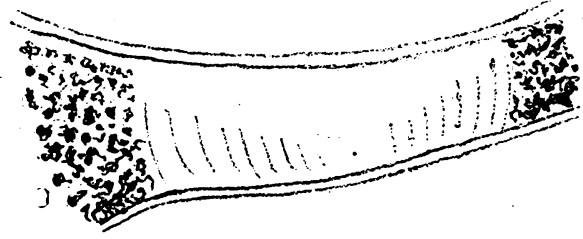

Fig. r.-Section of normal rib cartilage.

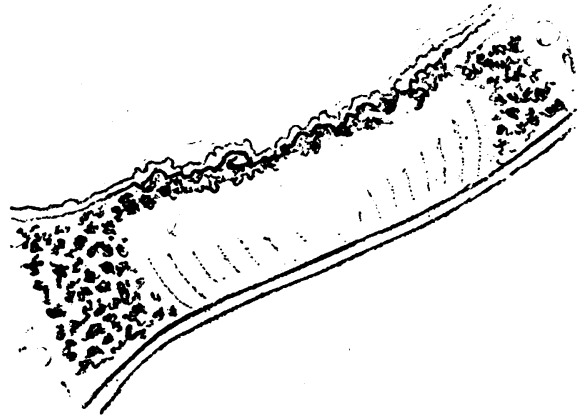

Fig. 2.-Ossification of rib cartilage proceeding.

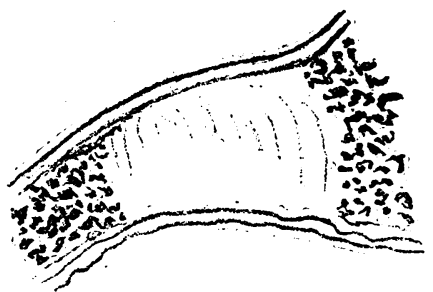

Fig. 3. Shortening of rib from partial ossification of cartilage.

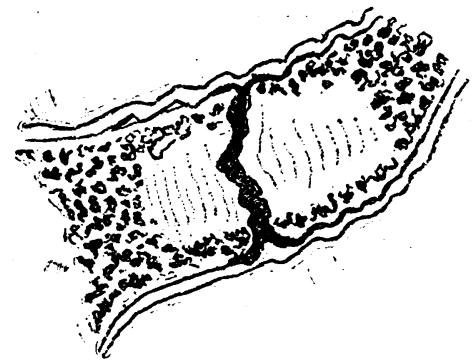

Fig. 4. Formation of false joint (pseudcourthrosis) in ossified rib cartilage.

it in a bony sheath. Both upper ribs becoming thus rigid, the upper opening of the thorax is stenosed and immovable, and all expansion upwards ceases, a condition of affairs which is very serious. But Nature comes to the rescue and forms a joint (pseudo-arthrosis), which you will see represented in Diagram 4, and thus some movement is restored to the thorax -a good example of the compensatory powers of Nature beneficently exerted in the present instance. These investigations have been carried on for years by Dr. Freund, and he possesses a large number of specimens of the ribs and cartilages in this condition. Uut of fifty necropsies at Leipzig and Berlin on phthisical patients he found that joint present in thirty which is a very large proportion; it was also found in different stages of development in most of the remaining cases. It is not difficult to perceive that the fixity of the thorax would give rise to local congestions and exudations in the lungs, and thus render them specially vulnerable to bacillary attack. Other anthorities in Germany have followed in the same direction, and they practically confirmed all his conclusions. When
I was in Berlin lately I was introduced to Dr. Freund by Professor Oscar Liebreich, when he kindly went into the subject. with me, and showed me some of his preparations.

There are many other causes which may bring about this condition. Pleurisy may cause it; pleuritic adhesions and anything which prevents the proper movements of the upper parts of the chest may give rise to it, and such cases are not. rare among those who follow sedentary occupations.

Another important question is, Why is it that we find the apices attacked first in lung tuberculosis?. The prevailing belief is that it is closely related to the comparative want of movement of the apices. But some recent writers say no, and urge that if that were so you ought to have more tuberculosis in men than in women, at any rate at the apices, because respiration in women is of the thoracic type, whereas men's respiration is chiefly abdominal. But this argument hardly applies to the apices, which are just as little used in women as they are in men. There is another theory which has been advanced by the late Professor Birch-Hirschleld, ${ }^{2}$ based on the anatomy of the bronchi of the upper lobe. The bronchi of the upper lobe in both lungs come off at almost a right angle, which causes some obstruction to both inepiratory and expiratory currents, and it is probable that the expiratory currents of the lower lobes meet the inspiratory of the upper, causing a certain amount of obstruction and stagnation in the npper lobes. The course of the bronchi to the lower lobes is more direct, and there would therefore be less chance of obstruction by the meeting of currents.

When you get tuberculosis of the lung how does it commence? Suppose the tubercle bacilli enter the trachea, and passing all these fine obstacles which we have been describing, they then go down into one of the bronchi. It appears from Birch-Hirschfeld's useful researches that it is in the terminal branches of the bronchi and the alveoli that you get the tubercle bacilli lodging and setting up pneumonic processes, with cell proliferation and a certain amount of exudation. The next thing which happens is that these bacilli break through the alveolar wall and enter the next alveolus, and carry their work of destruction further, uniil in time a cavity is formed. The question is, Where does the disease commence in the lungs? These preparations: which I have brought for your inspection give you some idea (series of lung sections shown). I am sorry to say I have never seen what ought to exist in most of the hospitals, certainly in chest hospitals, a series of preparations showing you how the tuberculous attack starts and grows, from the primary lesion onwards. Such a set can be obtained from necropsies in various hospitals, not only from Brompton, but from the general hospitals, from patients who die from other diseases, such as fevers. In such cases very often there are found lesions of early tubercle in the lungs. A complete and most instructive series of that sort could be formed without much trouble. I have here a specimen which shows you very well how the tuberculous lesion is formed. The primary lesion is about $I \frac{1}{2}$ in. below the apex. I will indicate by the marking pencil on this patient's chest where you may expect to find the first evidences by physical signs of tubercle.

The first place I should be likely to find a tuberculous lesion is in the npper lobe, $1 \frac{1}{\text { in }}$. below the posterior apex in the supra-scapular region. Here is a case where it was noted there. The next most likely place would be above the clavicle. And, lastly, you will be likely to find it in the first intercostal space. The focus might remain limited to the upper lobe for some time before spreading elsewhere. Next, in what direction does the mischief spread from the primary lesion? Generally anteriorly downwards to the level of the third rib, and the signs are limited to that spot for a long time, showing the upper lobe only to be affected. The phys1cal signs remain for a time above the supra-scapular ridge, another boundary of the upper lobe. With regard to the further advance of disease, as Dr. Fowler has well pointed out, the advance is commonly along the interlobar septum, and the reason I draw your attention to that is because very often medical men examine the chest anteriorly and posteriorly without examining the axilla. But it is when the attack is going on in the way $I$ have described that you are apt to get axillary cavities. When you have been listening for some time and not heard anything fresh below the third rib in front, you may think everything is perfectly quiet, but to your surprise you discover a large amount of crepitation down in the axilla; and, indeed, there may be a cavity forming there, which you have hitherto overlooked. There are many curicsities about the attack. For instance, the top of the lung may be attacked, and then you may get 
the corresponding portion of the upper part of the lower lobe attacked very soon afterwards. Why that is I cannot tell you. It may be due to circulation or to inhalation; but there is the fact; and you sometimes find in a lung a curious condition of things, namely, that in the apices, or in one apex, the disease is in a condition of arrest, but you may find fresh tubercle at the base of the top lobe. I have noticed that fact more than once. But the usual thing is, that the apex becomes affected, and then the disease spreads down along the interlobar geptum to the axilla. Next, you find that it will spread in front, the crepitation extending down to the third rib, or from the third to the fifth ribs; and then it goes almost to the base of the lung. In most of these cases you get in the upper part a cavity formed, and racemose tubercle extending down to the base. The question arises, why in some cases you get both apices affected quickly, and the rest of the lung remains unaffected for some time. That leads me to the other point-namely, how tubercle spreads? There are four ways in which it spreads. The first way we will call spread by continuity. That is very much like the picture I send round. You can see how they spread from one point to another. Spread by continuity is the commonest form. The second form of extension would be by means of the lymphatics. I refer to the lymphatics of the lungs themselves. You get a cavity formed in the lung, and then there are a series of small nodules of tubercle forming round it; just like the solar system, with the sun in the centre and the planets around. The disease is always very limited round that cavity. A and given rise to all these fresh centres of tuberculosis. Dr. Arthur Latham ${ }^{3}$ holds that the spread of tuberculosis in the body is by the lymphatic vessels and the lymphatic qacunae. The third form of spread is by means of the circulation. That is a dreadful and irresistible form, and that is the form when you see tubercle connected with some vessel in the lung, by means of which the bacilli are carried to different parts of the body. That is the form which causes taberculous meningitis, where you see a chronic case of phthisis in a middle aged man with a cavity in his lung not very large, and the patient is apparently going on quietly, but one day develops head symptoms. When you go to him you find he has symptoms of acute meningitis from which he dies. After death it is found that the meninges of the base of the brain are scattered with fresh tubercle. Remember that when both apices of the lungs are affected with tubercle, the cause must be through the circulation, certainly in the early stage. Now and then that is very strikingly seen. I have seen patients going on quietly, then something acute has taken place, there is a breaking down of one lung and some of the bacilli are carried to the other lung which quickly becomes infiltrated with fresh miliary tubercle. The fourth form is srom the reinhalation of sputum. I have so often talked about that in this room that I shall not dwell upon it very much now, because I have already shown you plenty of specimens. But remember the great feature is this: suppose there is a cavity in the lung which does not empty itself completely, and the patient is weak and cannot expectorate properly, the expectoration rises to the junction of the two bronchi, and then perhaps an inspiration will carry it the wrong way: at any rate it falls into the other bronchus and sets up another focus of tuberculous disease. This probably goes on to cavitation and then these are described as secondary cavities. That process may take place in any part of the lung.

diagnose a case of phthisis? We must look at it in all its aspects, and we must not forget the history, the initial signs in most of the cases are crepitation and slight dulness in the supra-scapular region. Many of the diagrams taken from my hospital patients exemplify to some extent the march of tuberculosis in the lung. In one, for example, the anterior portion of the left upper lobe was first affected, there being dullness and crepitation to the third rib, and noother signs. Other diagrams illustrate crepitation in various parts of the lung, where the disease started from above and spread downwards; also the way in which crepitation is found in the two inter-scapular regions, and where crepitation has extended to the base of one lung without the other lung being affected, which is a rare event. Another diagram illustrates a case in which there was acute emphysema, which is always a difficulty in connexion with phthisis and its recognition. But I have one diagram which shows how, in spite of the emphysema, dullre:s appeared in the supra-?capular region, and was the key to the diagnosis. In another case the suprascapular region was early effected, the mischief spreading by continuity downwards. Yet another shows tuberculization of the whole lung without any breaking down to speak of, so that no cavity could be made out.

Now to return to the question of diagnosis, of course, you must go into the history of the patient. If you can discover that there has been fever and night sweats and so forth, it will be easier. But you will often find that although the whole symptoms are suspicious there are none which you can absolutely rely upon in the history. Take the one symptom which was long relied on-fever. There are plenty of cases of early tuberculosis which have no fever at all. If there is anything characteristic in such patients, it is that the temperature is below normal. Some of the lowest temperatures which have been recorded have been in early cases of phthisis. I remember a case of mine which I recorded in which the temperature was taken most carefully, and was found to be $91.8^{\circ} \mathrm{F}$. But the late Professor Lebert went one better than that, for he recorded one of $89^{\circ} \mathrm{F}$., and you know he was a very careful observer. So you can rely upon the temperature. If I were asked what was the characteristic temperature of phthisis I should say that it was one of extremes, but that a low temperature is quite as indicative of phthisis as a high temperature. But if there is pyrexia in phthisis then it follows certain rules, which I need not go into now. With regard to wasting, that may arise from various causes. Continuous cough is a very important item, especially in conjunction with night sweats and malaise and wasting.

\section{Examination of the Sputum.}

The important item nowadays is the sputum, which has to be examined carefully and frequently. In the early stages of phthisis you may examine the sputum of an undoubtedly phthisical patient for some time without finding any tubercle bacilli, but you will be successful in the long run. If you find tubercle bacilli in the sputum, there is no doubt about the diagnosis. But the quantity of bacilli found in the sputum is no measure of the severity of the disease process. Where the bacilli are plentiful, there is probably a cavity, on the walls of which they multiply and are easily expectorated. Therefore, for diagnosis, we have to depend very largely upon physical signs, which after all have served their purpose wonderfully well. It is interesting to remember the time when physicians had little idea of diagnosing phthisis, when it was confused with bronchitis and pneumonia. We now know that many of the cases which were called bronchitis in the early days were really instances of consumption. I remember my father once telling me that, on his return from studying auscultation under Laennec at Paris, he was entrusted by two leading London physicians of the day with a patient suffering from something in the throat and a little bronchitis, as it was described. My father said he suspected from the look of the patient that there was something more the matter. The physicians had not examined his chest, as they did not believe in the new methods of examination, but decided to send this patient off to Madeira for bronchitis and sore throat. Before starting for Madeira, my father examined the patient's chest, and found considerable infiltration of a tuberculous nature of one apex and a large cavity in the other. So he very properly reported to the physicians what he had found, and stated that he would be very much surprised if he brought that patient back alive from Madeira. There was not much treatment of consumption in those days, most consumptive patients died in a few months. In this case it only proved too true. The patient was fairly happy at Madeira, but he gradually dwindled away and died there. That looked rather bad for the doctors who originally sent him there. It shows also what an enormous amount of knowledge we have gained by the introduction of physical signs.

\section{Physical Signs.}

We must bear in mind about the physical signs that it is their locality rather than their character which is of importance. Signs which you would think nothing of at the base of the lungs are very serious at the apex. For instance, a friction sound occurring at the apex is very common. The question arises; is that pathognomonic of tubercle? Apical pleurisy has been long a matter of discussion. There is no doubt that every now and then you may get a case where a well marked pleuritic rub is heard at one apex, and yet 
nothing comes of it. I suppose some adhesion takes place, and beyond the fact that the apex is not expanding as well as the other portions of the lung, and the breathing is somewhat obstructed, you can hear nothing abnormal. I think most of these cases are tuberculous. The few. I have been able to follow out have undoubtedly been cases of tuberculosis. I always look upon apical pleurisy with some suspicion. It is more especially suspicious if you find it at one apex only. If you find it at both apices, with a good deal of friction, I think it probably accompanies pneumonia, or it might be simply pleurisy

Bronchophony.-Bronchophony is sometimes very characteristic, and when it is heard over the apex it is of serious import, as it means that the consolidation is extensive. It is very seldom you detect bronchophony at the apex. When you hear it anywhere else in the lung it generally means consolidation, and if heard over the upper lobes, consolidation of a tuberculous nature. Where bronchophony is most useful in diagnosis is in a case with highly resonant chest, and where crepitation is audible over the whole of one side, and perhaps is a little more marked on coughing. If bronchophony be also present, you may be fairly certain that the case is tuberculous. Very often these are secondary cases, cases in which the patient is suffering from some other serious illness, such as typhoid fever, and you are called in to offer an opinion on the lungs, and you find to your horror a lot of crepitation in one lung, and the patient much wasted with fever. You ask, is it tubercle or is it pneumonia?. If you find no dullness at all and no other signs, but the combination of scattered crepitations and bronchophony, you may besure the case is tuberclous. I have never known an exception to that in my experience. Otherwise bronchophony is not so very valuable, and $I$ will tell you why it is not so. There are certain people who have vibrating bronchi, or at all i events vibrating walls of the chest. It is most extraordinary, but they always have vocal vibration and bronchophony, and in such people if you put your hand on to their backs with their clothes on, you can feel the vibration right through, and if you auscultate them you will hear bronchophony. These sounds are heard again and again over most of the thorax, and it is obvious that in such patients you cannot talk about vocal vibration and bronchophony. There is no reason to suppose that these people have consolidated lungs. They are generally nervous and highly-strung people, and in them I know I must not use the voice sounds when examining them for tubercle.

Different Forms of Respiration.-Much is said about prolonged expiration, and also about tubular breathing and bronchial breathing. The term I generally use is "tubular breathing." I think it was Laënnec who used it first: but I learnt it from my father, Dr. C. J. B. Williams, and found it very useful. The cavernous breath sound is hollower and louder, and prolonged expiration is simply a long-continued expiration. Tubular breathing is something between the two. Patients, unless instructed how to breathe noiselessly, often make a sound with their mouths which might be mis taken for tubular breathing, but this can easily be avoided.

Obstructed Respiration.-But there is another sign which ought to be remembered, and which you do not often see mentioned in books. You listen over a spot, particularly the apex, when respiration ought to be clear, and you hear nothing, or hardly any breath sound; and that surely means something; because if after the patient has coughed and taken big breaths, and you cannot hear anything except a very feeble distant sound, you are sure there is something abnormal and that the bronchus must be blocked.

Crepitation.-In regard to other sounds, some of the books tell you that one of the early sounds of phthisis which you detect on auscultation is prolonged expiration or tabular sound at one apex. That is not my experience. My experience is that the earliest sound in most cases is that of a crepitation, or the crepitation which you hear on coughing. Very often you do not hear it until the patient coughs. If after the patient has coughed you hear this liquid sound or râle, generally.accompanying expiration, at one apex, and it persists in spite of all the coughing, that is a very serious sign indeed, ar I I know no auscultatory sign which is so pathognomonic of tuberculous disease as that. I should not say it would be pathognomonic in other parts, but certainly in the apices I look upon it as being an indication of the presence of tubercle. In fact liquid sounds are more important in these cases than dry sounds. You should not auscultate any patient without making him cough freely, and many of $n \cdot y$ patients complain that they are rather exhausted after examination chiefly because of the amount of coughing I make them do. You may percuss these people and make them breathe and so on, but if you do not make them cough you may not hear this râle.

Dullness.-I have left dullness till nearly the last because, although when it is present it is very important, still, in many cases of phthisis, there is no dullness at all. Where are you to look for dullness? If you find it over the supra-scapular region, that is at once something decisive. It is all very well when it is at one apex, for that is a proof that there is consolidation and that it is probably tuberculous; but very often it is present in both apices, and you mav get confused and think that there is no dullness after all. You may argue that the supra-scapular region is never very resonant, and that. you have laid too much stress on its lack of resonance. But very often there is consolidation at both apices in such cases. If you find the first interspace on both sides dull, all you can do is to compare it with the nipple region. Thus you get a second or third spot and compare them with the first. Now, where is the dullness to be found? This is a point I want to lay great stress upon. You may find it on the clavicle itself. Percuss the clavicle carefully, for andoubtedly on the outer half of the clavicle you may find it. This clavicular region is also where you can sometimes detect bronchiectasis. But even there you may go wrong, because if you have a chain of stramous glands they reach down under the clavicle and give rise to dullness. But you very seldom find an enlarged gland here without finding the glands in the neck enlarged also. Never forget in doubtful cases to percuss the clavicle itself. I have known cases where the only place at which dullness could be elicited was over the clavicle. We must not forget that hyper-resonance is quite as often present in the front portions of the chest as dullness, owing to the existence of emphysema. I am not now speaking of cavities, for the physical signs of cavities is a large subject, and which I shall deal with in another lecture. In examining a patient in the early stages of phthisis the great points are to make him cough, and be on the look out for the crepitation or rale. Bronchophony is valuable up to a certain point. If you find dullness in any of the upper regions, that fact is very suspicious. I remember having a case of prolonged expiration which deceived me, in which the sound was heard in the supra-scapular region. I thought it probably occurred in connexion with tubercle, but there was no dullness at all. It was in a child. I treated the child with potassium iodide, as I had some suspicion of enlarged bronchial glauds. At the end of a month that prolonged expiration disappeared, so I concluded it was due to enlarged bronchial glands.

The Diagnosis of Tubercle from Pneumonia.

It is not very difficult to distinguish tubercle from pneumonia. The position of the consolidation is so very different in the two conditions. In pneumonia the consolidation is at the base of the lung, not at its apex, and the crepitation is of a different character. What you hear is a number of crepitant. sounds crowded together, not one sound but many sounds. But in tubercle you hear one râle at a time. Then there wil be the history and the examination of the sputum to help you.

The Diagnosis from Bronchitis.

But there is a great difficulty in regard to cases of what is called catarrhal phthisis. A patient comes with a history of phthisis, and you examine the chest, but you find nothing but hyper-resonance and catarrhal sounds, and this is where the sputum examination comes in very usefully. But in addition you have to watch the bronchitic signs, the sonorous rhonchi, sibilant sounds, and so on, and ascertain whether they are all over the chest or whether they are limited to one side. Where you have bronchitic sounds limited to one side, particularly to the posterior region, and the upper portion, they are suspicious of phthisis. These are most troublesome cases, because you watch day after day, but still the signs of the acute bronchitis mask everything. After the signs of bronchitis have passed away you examine the chest carefully, and find to your horror that there is a cavity which you have not been able to detect previously, and have not been able to. trace the steps which led up to its formation. These are notonly troublesome, but they are very unfavourable cases, which you do not get much credit by. I have had cases in which the patient's friends complain that the family doctor said it was bronchitis, and when I see the patient I find evidence of a considerable cavity. I, of course, point out that it is very difficult to recognize such cases in early stages, and as long as the signs of bronchitis are present they are likely 
to mask the tuberculous lesion. But you should always be suspicious of such a case if the signs are on one side only. One point which you may note is that the sonorous rhonchus frequently ends with a prolonged expiration. If you hear that, you may take it as pathognomonic of phthisis. With regard to enlarged bronchial glands, there is not much trouble, because they never cause râles at the apex, and generally speaking the sounds due to bronchial glands are found in other regions.

The Diagnosis from Mediastinal Tumours.

The question of mediastinal tumours I need not go into fully here. The symptoms of these tumours are so very different from those of tuberculosis, and the same may be said of aneurysm. I have seen cases in which aneurysm has been overlooked, and I have seen cases of supposed aneurysm in which the signs were produced by consolidation, which had been overlooked.

The Diagnosis from Typhoid Fever.

The question of typhoid fever from a diagnostic point of view has more bearing on acute tuberculosis than ordinary pulmonary phthisis. The history of such cases does not tell you very much, but when you watch the temperature charts in the two conditions you will find them very different. The typhoid-fever chart shows a higher and more continuous temperature. As a rule, the consumptive chart shows a low temperature in the morning, rising towards mid-day and up to 2 or 5 o'clock, or it may rise to as late as 8 o'clock, and then falling rapidly from then till the next morning. That is the general run of temperature in a phthisical patient. Of course the temperature varies according to the amount of ouppuration present, the pyaemic chart being mingled with the tuberculous. Anaemia is the last condition which it is necessary to bear in mind; here the absence of wasting and the presence of physical signs will settle matters.

\section{REFERENCES.}

1 Beiträge zur Histologie der Rippenknorpel, ${ }_{18} \varepsilon$, and later works. 2 Deut Arch. f. klin. Med., Leipzig, r9g, Bd. Ixiv, s. 58 . ' 3 Points in the Etiology of Tuberculosis, Edin. Med. Journal, November, rgoz.

\section{THE NATURE OF THE INFECTIVITY OF PHTHISIS : A STUDY OF THE VIEWS OF KOCH, FLÜGGE, AND OTHERS.}

BY ALFRED HILLIER, M.D.EDIN.,

Visiting Physician, London Open-air Sanatorium; Member of the Council of the International Bureau for the Prevention of Tuberculosis.

Althotgh views as to the infectivity of phthisis attained no scientific measure of accuracy until within quite recent years, there are historical records of such views being held long before the bacteriological period of pathology. For instance, in the eighteenth century, principally owing to the teaching of Morgagni, both in Italy and Spain, phthisis was recognized as an infectious disease, against which most stringent precautions were taken.

Inhalation of TUBercle Bacilli.

Klencke and Villemin ${ }^{1}$ both demonstrated the inoculability of tuberculosis, but to Robert hoch is due the crowning honour of having in 1882 isolated the tubercle bacillus. The results of the experiments which led to this discovery are set forth at length in the masterly essay entitled The Etiology of Tuberculosis. ${ }^{2}$ These researches are too well known to need recapitulation; but as having a special bearing on the subject of this paper I will briefly call attention to what the essay has to say on inhalation experiments. Experiment 26 is thus described:

A very roomy box, having on one side an opening for the oriflce of the soray apparatus, was placed in a garden at a good distance from any habitation. The spray apparatus was placed outside the box, with its orifice projecting into the interior. The apparatus was connected by means of elastic tubing and a suitable length of lead pipe, which passed through the woodwork of a closed window, with the indiarubber bellows, and so could be worked from the room beyond the region of the spray.

"Pure culture from a phthisical lung in the human subject, No. I (carried through twenty-three generations in fifteen months), rubbed up with distilled water, and the fluid diluted to such an extent that it looked almost clear. Any visible fragments present in the fluid subsided a,ter standing a short time; the upper layer, which showed hardly any epagitst vas; poured off and used for inhalation. Fifty c.cm. were dis persed in the course of half an hour on three successive days, and inhaled by the animals in the box as follows : 8 rabbits, to guinea-pigs, 4 rats, and 4 mice. After the inhalation the animals were kept in separate roomy cages and well looked after. In some of the animals dyspnoea appeared after ten days, and 3 rabbits and 4 guinea-pigs died in the course of fourteen to twenty-five days. All the remaining animals were killed twenty eight days after the last inhalation. All the rabbits and guinea-pigs had numerous tubercles in the lungs, the size of the tubercles being proportionate to the length of time the animals had lived after inhalation.

A more convincing proof of the highly-infectious character of sprayed tubercle bacilli could scarcely be asked for. But at this still early stage of research Koch was not led to draw any strong distinction between the effect of the inhalation of sprayed tubercle bacilli and the inhalation of tuberculous dust. Nevertheless, Professor Koch's comment on the results obtained by Experiment 26 call for note and consideration here. Thus he says:

There can likewise be no doubt as to the manner in which the tuberculous virus is carried from phthisical to healthy subjects. By the force of the patient's cough particles of tenacious sputum are dislodged, discharged into the air, and so scattered to some extent. Now numerous experiments have shown that the inhalation of scattered particles of phthisical sputum causes tuberculosis with absolute certainty, not only in animals easily susceptible to the disease, but in those also which have much more power of resisting it. It is not to be supposed that man would be an exception to this rule; but, on the contrary, we may surmise that any healthy person brought into immediate contact with a phthisioal patient, and inhaling the fragments of fresh sputum discharged into the air, may be thereby infected. But probably infection will not often take place in this way, because the particles of sputum are not small enough to remain suspended in the air for any length of time. Dried sputum, on the contrary, is much more likely to cause infection, as, owing to the negligence with which the expectoration of phthisical patients is treated, it must evidently enter the atmosphere in considerable quantity. The sputum is not only ejected directly on the floor; there to dry up, to be pulverized and to rise again in the form of dust, but a good deal of it dries on bedlinen, articles of clothing, and especially pocket handkerchiefswhich even the cleanliest of patients cannot help soiling with the dan. gerous infective material when wiping the mouth after expectorationand also is subsequently scattered as dust.

From this it will be seen that while Koch from the outset recognized the possibility of infection occurring both from bacilli coughed out by the consumptive and from the dried pulverized expectoration, he regarded dried sputum as the most fruitful source of infection.

The view with regard to the danger of pulverized sputa here enunciated has in one form or another been adopted by a series of writerg down to the time of Flügge.

Tappeiner, Thaon, Cornet, and Straus have all supported this view. At this stage it is interesting to note that we now have on record two unintentional but nevertheless crucial experiments on man. The one showing the danger of inhaling artificially sprayed tuberculous sputum; the other showing the deadly character, when inhaled, of powdered tuberculous material.

In the one ease Tappeiner lost a servant, who, after carelessly handling the apparatus for spraying tuberculous sputum, was attacked with an acute onset of pulmonary tuberculosis and died. In the other case, Nocard ${ }^{3}$ relates that Thaon, while experimenting on the effect of tuberculous dust upon animals, himself fell a victim to it, and was seized with an attack of tuberculous broncho-pneumonia, which proved rapidly fatal.

Space will not allow of my dealing with all the experiments made. Many of them are described at great length in Straus's ${ }^{4}$ large work, and I will refer to a few as illustrating this point. Thus Tappeiner used the spray experiments in 1877 , in Buhl's laboratory at Munich, and was followed in this form of experiment by Weichselbaum ${ }^{6}$ and Veraguth, ${ }^{6}$ who all obtained positive results.

In $1883^{7}$ Dr. Arthur Ransome stated that he had discovered by microscopic examination the presence of taberele bacilli in the expired air of advanced phthisical cases, the vapour of which had been condensed by a freezing mixture. Dr. Theodore Williams ${ }^{8}$ also detected a certain number of tubercle bacilli in the air of the wards of Brompton Hospital.

I now pass on to a series of experiments conducted in the years 1897 and 1898 by a gronp of observers, the results of whose work are dealt with by Flügge. In 1×9g Flügge published a summary of a series of experiments on the infectivity of phthisis (a) through the inhalation of powdered desiccated tuberculous sputa; (b) through the inhalation of the minute drops sprayed by the coughing, speaking; or similar breath movements of a consumptive patient." In these experiments Flügge was assisted by Sticker, Heymann, Laschtschenko, and Beninde; who worked in his laboratory at Breslau pnder his directions. 